Swarthmore College

Works

\title{
Fate Maps, Gene Expression Maps, And The Evidentiary Structure Of Evolutionary Developmental Biology
}

Scott F. Gilbert

Swarthmore College, sgilber1@swarthmore.edu

Follow this and additional works at: https://works.swarthmore.edu/fac-biology

Part of the Biology Commons

Let us know how access to these works benefits you

\section{Recommended Citation}

Scott F. Gilbert. (2007). "Fate Maps, Gene Expression Maps, And The Evidentiary Structure Of Evolutionary Developmental Biology". From Embryology To Evo-Devo: A History Of Developmental Evolution. 358-374. https://works.swarthmore.edu/fac-biology/440 
Fate Maps, Gene Expression Maps, and the

Evidentiary Structure of Evolutionary

Developmental Biology

Scott F. Gilbert

The Mapping Heritage in Embryology

The mapping concept is one of the most important devices threading its way through classical embryology, developmental biology, developmental genetics, and evolutionary developmental biology. Mapping is, of course, a metaphor referring to the practice of cartography, the construction of a two-dimensional representation of a three-dimensional surface. In their public use, maps attempt to accurately scale the political or geographic dimensions of a territory so that the user of the map can obtain an overview of the political or physical landscape. Maps emphasize boundaries and distinctions - where the land terminates and the sea begins, at what point the laws of Germany end and the laws of France take effect. Mapping is thus an attempt to depict on paper the boundaries that exist in the social or natural world. Needless to say, mapmaking has always been a political act, and no representation is ever completely without its abstractions and exaggerations. ${ }^{1}$ Unlike "normal tables," which they superficially resemble, "maps" are not merely depictions of the embryo. Rather, they are the superposition of prospective fate or gene expression upon the depiction of the (usually early) embryo. Thus, the two major types of maps used in developmental biology have been the "fate map" and the "gene expression map."

Fate maps are the attempts of embryologists to identify the cells that produce certain adult or larval structures, and to label them as such on an early-stage embryo. In other words, embryologists make a map of what is to be and superimpose this data onto a map of what is yet to develop. Examples of fate maps are shown in figure 11.1 .

Cell fate-mapping started with tracing cell lineages, the identification of cell fate by observation alone. ${ }^{2}$ This was done, for example, by E. G. Conklin at the Woods Hole Marine Biological Laboratory. Conklin's analysis of the tunicate embryo in 1905 was a landmark in the field. Often, these data were depicted as a dichotomously branching tree (figure 11.2A), 


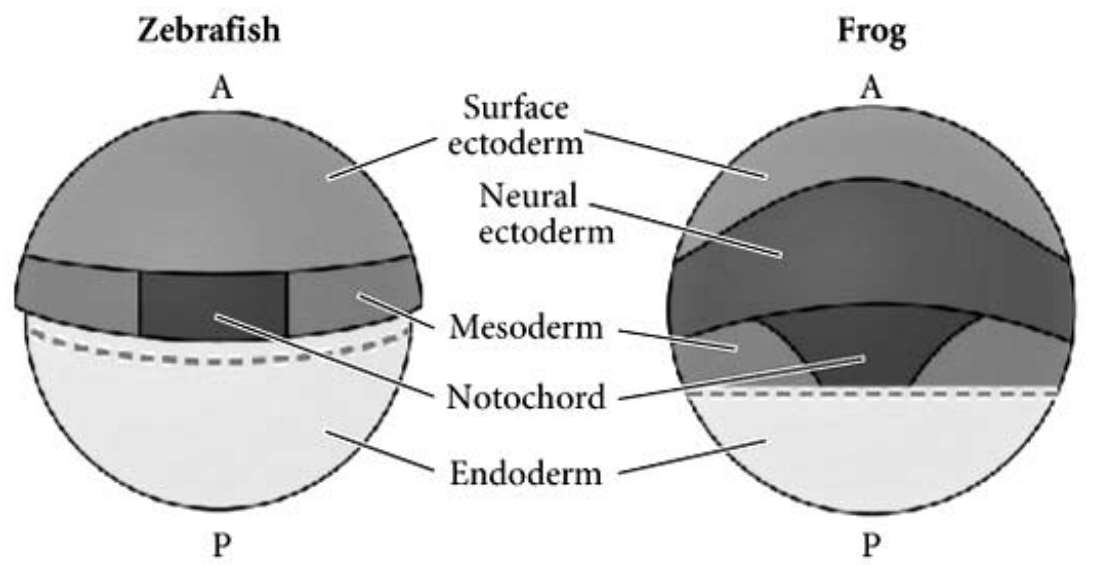

Figure 11.1

Surface fate maps of frog (Xenopus) and zebra fish (Danio) embryos at the early gastrula stage on the dorsal surface. These and the other illustrations are taken from Gilbert (2000).

thereby placing the data into the standard format of taxonomic field keys. The data of these "trees" could later be superimposed onto the early embryonic cells, and made into a fate map (figure 11.2B). In 1933, Conklin used the data collected in 1905 to make one of these summary fate maps. Cell lineage fate maps were also used by Hörstadius in the 1930s to show the fate map of the sea urchin embryo.

Walther Vogt constructed the first systematic fate maps when he applied vital dyes to the early amphibian embryo. ${ }^{3}$ He made agar chips impregnated with a vital dye and then placed the egg in a wax depression so that he could place chips onto the egg and impart dye to a specific region of the egg or embryo (figure 11.3). In this way, he was able to mark cells early in development and see what they became later. $\mathrm{He}$ found that cells in similar areas gave rise to similar nearby structures. However, there were also boundary lines, such as those where ectoderm ended and mesoderm began. It is easy to see why these were called fate maps. Vogt's fate maps looked very much like globes. They had two polesthe animal pole and the vegetal pole- and an equator down the center which served as a landmark. ${ }^{4}$ Even today, this geographic view of the amphibian egg is the most common representation. It is difficult to avoid seeing the egg as a globe, and why bother to avoid it? In amphibian embryos, the divisions are orthogonal, dividing the egg by lines of latitude and longitude. The prime meridian-literally the first cleavage plane- 


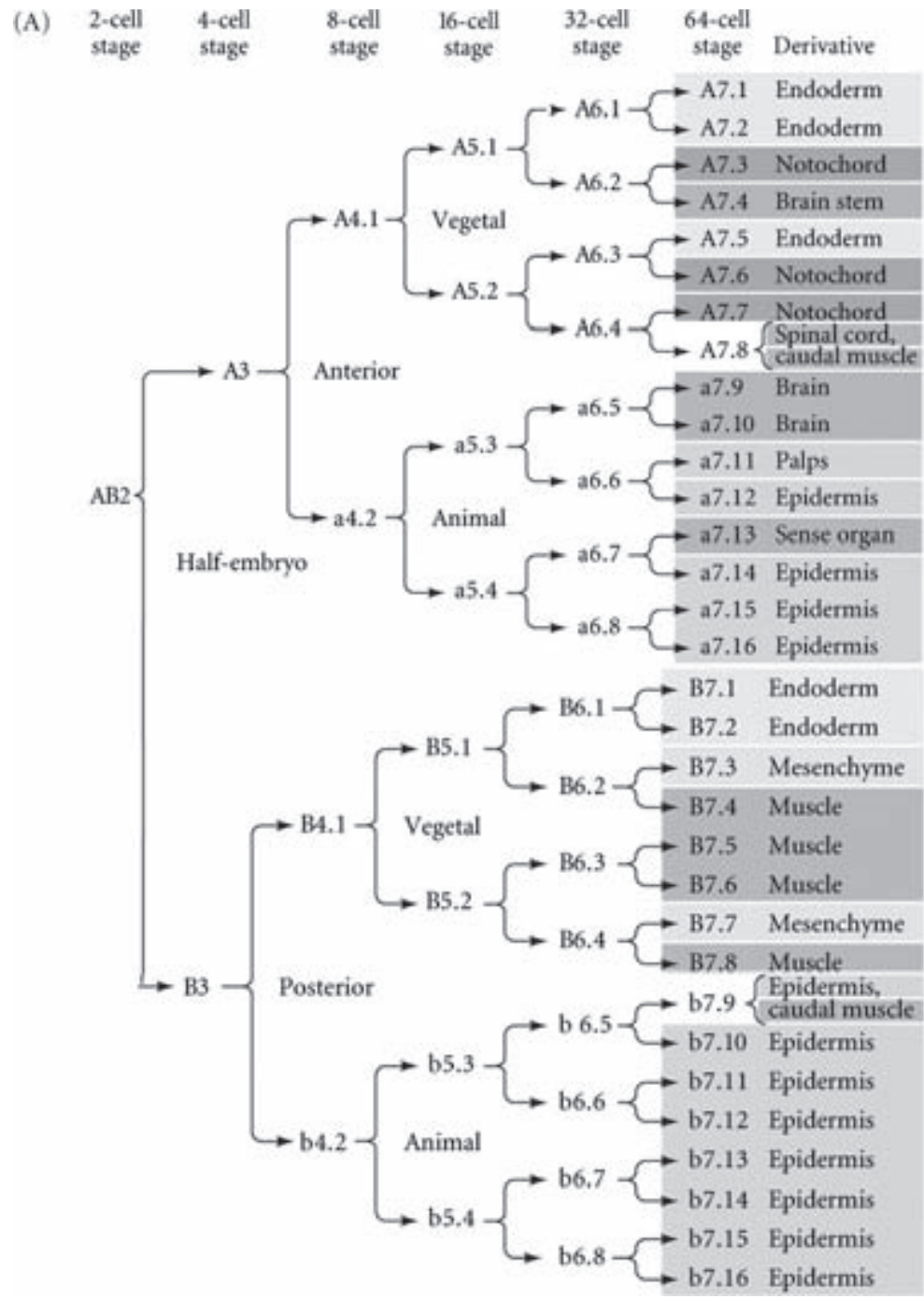

(B)
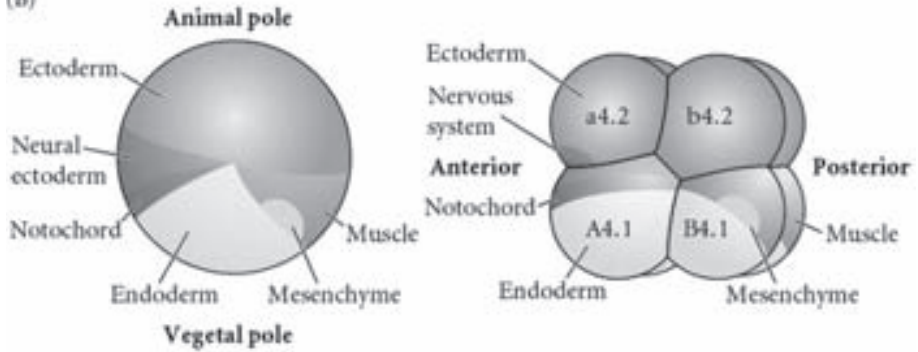

Figure 11.2

Fate map of the tunicate embryo. (A) Dichotomous branching lineage diagram of the tunicate Styela. (B) Fate map constructed by superimposing the fates onto the onecell and eight-cell embryos. 

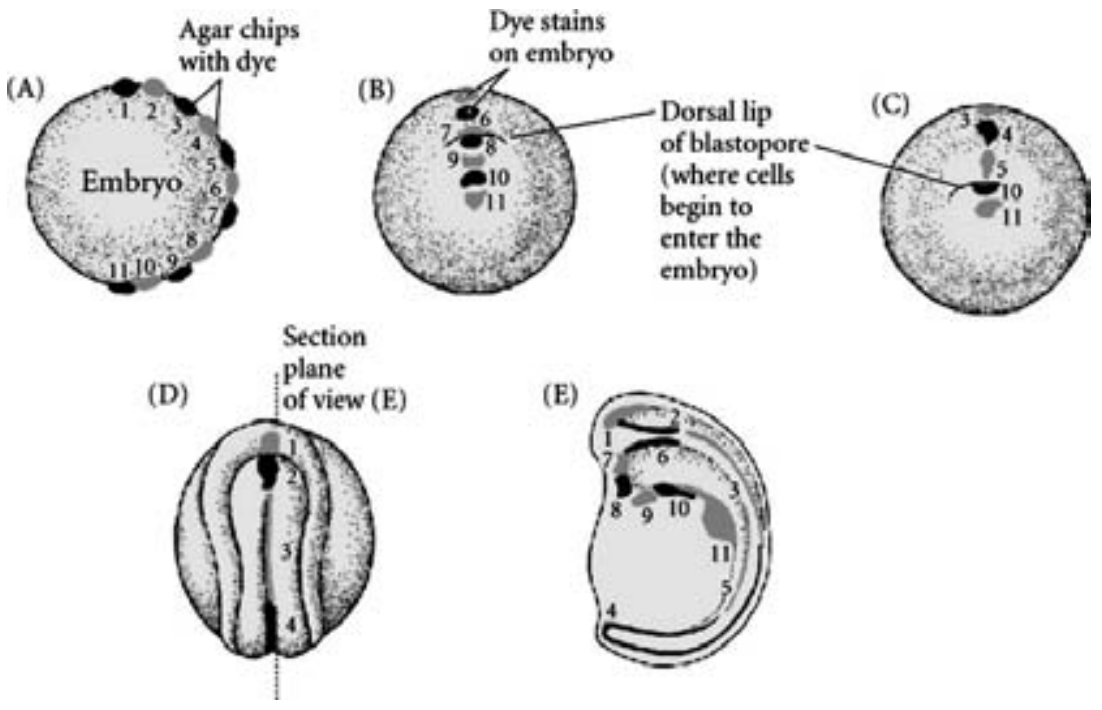

(E)

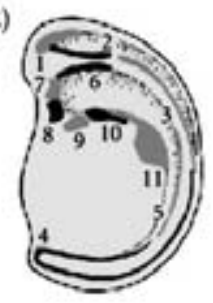

Figure 11.3

Vital staining of a newt embryo to produce a fate map. (A) Vogt's method for marking specific regions of the embryo with dye-impregnated agar chips (B-D) Dorsal surface views of successively later embryos. (E) Newt embryo dissected to show stained cells in the interior.

bisects the gray crescent and separates the embryo into its future left and right sides.

Modern investigators still make fate maps, and the preparation of a fate map is usually one of the first steps in any research program. The dyes have become better (less diffusible, longer lasting), and the resolution has attained the single-cell level. ${ }^{5}$ We can now label individual cells of the early embryo and find out what their descendants become. Moreover, this is not of just historical interest. There are still heated debates over fate maps. The location of the blood-forming cells of Xenopus is contested, ${ }^{6}$ and the endoderm-ectoderm boundary of sea urchin embryos has only recently been determined. ${ }^{7}$ Some researchers have criticized the attempt to place complex three-dimensional fates onto the global surface. Bauer and colleagues ${ }^{8}$ point out that it is not correct merely to project a later-stage fate map back to cleavage stages, and they document inconsistencies in the literature that might be due to researchers' having uncritically projected later cell positions onto earlier embryonic stages.

Moreover, the geomorphic amphibian fate map of Vogt turned out not to be universally applicable to other amphibians. For years, the fate 
map of Xenopus was expected to be patterned totally according to the surface cells. After all, the rocks a mile below the surface of the United States are not the province of some other country. We even claim the air space above our nation as our own. However, this was found to be false in Xenopus. Here, the fate map of the internal cells differed from the fate map of the external cells. ${ }^{9}$ The geographical assumption turned out to be wrong. Fate maps are being refined, revised, and constructed for new organisms. It has been an ongoing research project from the 1920s to the present.

Good fate maps are absolutely critical in embryology and evolutionary developmental biology. As Viktor Hamburger ${ }^{10}$ pointed out, the first time Spemann interpreted his results of the dorsal blastopore lip transplantation, he got it wrong. Spemann had used a very primitive fate map, and he had thought that the cells above the dorsal blastopore lip were fated to become neural ectoderm, not dorsal mesoderm. It had to be pointed out to him by a colleague, Hans Peterson of Heidelburg, that a revised fate map-one that Spemann himself had devised in 1921-suggested these cells were fated to become mesoderm. That single fact completely changed the interpretation of his results, and the confirmation of that later interpretation-Spemann and Mangold's paper ${ }^{11}$ — became one of the most important experiments in modern embryology. One of the earliest experiments in evolutionary developmental biology (and, for that matter, in the area of development genetic) was the famous Spemann and Schotte experiment ${ }^{12}$ wherein they transplanted prospective jaw tissue between salamander and frog embryos. The frogs had newt jaws and vice versa. For the experiment to work, the position of the prospective jaw had to be carefully defined.

When fate maps are compared, evolutionary change can be inferred. This was done by Tung and colleagues, ${ }^{13}$ who compared the vital dyederived fate map of Amphioxus with the lineage-derived fate map of the tunicate Ciona. The results showed similarities that were unexpected on the basis of the mode of cleavage, but were expected on the basis of evolutionary phylogenies. More recently, Greg Wray and Rudy Raff ${ }^{44}$ compared fate maps to show the changes in blastomere fate during early development of direct-developing sea urchins. They showed that the fate map of the direct-developing urchins had been changed so that the cells that would have formed larval ectoderm were forming the vestibular structures that become the adult. Moreover, the positions of neuronal precursors had been altered. The fact that these species diverged only around 10 million years ago showed that significant developmental change can occur 
through altering early development, something that had formerly been thought to be impossible.

\section{Gene Expression Maps}

A related, albeit chronologically later, program is the mapping of gene expression patterns. There are many ways to map gene expression, and they usually give a direct projection upon an embryonic surface. The most common way is through in situ hybridization. Here, one can actually stain for the accumulation of a particular type of mRNA. This is an incredible ability, and it has revolutionized developmental biology. One obtains a probe that is complementary to the mRNA and labels it with a reporter molecule. The probe and its reporter accumulate only at the sites where the target mRNA has accumulated. A second way is to use a reporter gene sequence. These are genes (such as those for bacterial $\beta$-galactosidase and jellyfish green fluorescent protein) that can be readily identified, are not usually made in the experimental animal, and are fused to the regulatory region of a particular gene. Wherever the gene is usually expressed, the reporter gene will be transcribed. These techniques have brought the notion of structure back into developmental biology. In the early 1980s, the evidence of developmental genetics consisted of bands on gels. Since the 1990s, evidence has consisted of radioactive grains on microscope slides or colored products on whole-mount embryos. One now has to know the structure of the embryo.

Gene expression maps have had very important consequences. One of them was to show that units of embryonic construction need not be the same units as the adult units of function. Thus, compartments, rhombomeres, internal ribs, parasegments, and enamel knots are anatomical regions of gene expression and function that have no obvious anatomical correlate in the adult. These regions of gene-expressing cells are critical in constructing the body. Without maps of gene expression patterns, we probably would not be aware of them.

Gene expression maps can serve several functions. The most obvious is that they can be used as fate maps. For instance, if one knows that the Brachyury and Twist genes are expressed in Xenopus and Drosophila mesodermal cells, one can look at which cells transcribe these genes and know that they will become mesoderm. Similarly, since only the notochordal cells of Xenopus transcribe the Chordin gene, a probe to Xenopus chordin can be used to locate cells that produce the notochord.

These gene expression data can provide extremely useful information about cell fate. Indeed, the fine structure of the organizer did not 
become known until gene expression data were merged with the more detailed fate maps of Xenopus laevis. It is now thought that in Xenopus, the cells of the organizer ultimately contribute to four cell types: pharyngeal endoderm, head mesoderm (prechordal plate), dorsal mesoderm (primarily the notochord), and the chordaneural hinge. ${ }^{15}$ The pharyngeal endoderm and prechordal plate lead the migration of the organizer tissue and appear to induce the forebrain and midbrain. The dorsal mesoderm induces the hindbrain and trunk, and the chordaneural hinge induces the tip of the tail. The expression patterns of transcription factors provided the key to how this was done. ${ }^{16}$ Vegetal plate rotation was required to put the Cerberus-expressing pharyngeal endoderm cells dorsal and anterior to those cells expressing chordin or Goosecoid. This revised fate map, ${ }^{17}$ made primarily by gene expression data, was published by Winklebauer and Schürfeld (figure 11.4), who found that the vegetal endoderm actively pushes a
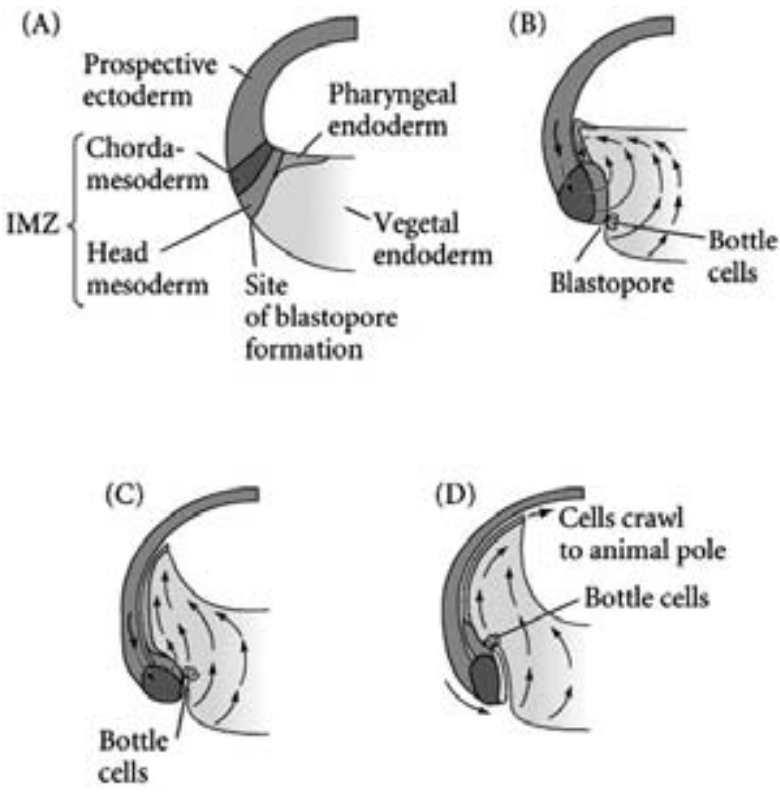

Figure 11.4

Early movements of Xenopus gastrulation, as shown by gene expression. The cells fated to form the pharyngeal endoderm express Cerberus. These cells are at the anteriormost point of the migrating epithelium, and are moved into this position by the rotation of the deeper vegetal cells. The cells fated to become head mesoderm express the Goosecoid gene, and they follow the pharyngeal endoderm. The cells fated to become chordamesoderm are expressing Xbra (Xenopus, Brachyury), and they follow the other two regions. 
region of endoderm up ahead of the mesoderm, causing it to contact the surface cells and migrate anteriorly to the mesoderm.

Gene expression maps need not be confined to fate maps, however. They also can be used to show signaling. Indeed, one of the most important uses of gene expression mapping has been to show which cells are signaling centers. In this analysis, the gene being expressed encodes a paracrine factor that is capable of influencing the development of other cells. The zone of polarizing activity in the chick limb provides a good case. Since the 1960s, it has been known that a small block of mesodermal cells at the posterior junction of the limb bud and the body wall has a remarkable ability: when it is taken from one limb bud and placed in the anterior margin of a second limb bud, the host limb bud develops two mirror-image sets of digits. This region was called the zone of polarizing activity (ZPA). Riddle and his colleagues ${ }^{18}$ in Cliff Tabin's laboratory showed that ZPA was defined by the expression of the Sonic Hedgehog gene. First, they showed that the Sonic Hedgehog protein is necessary and sufficient to account for the ZPA's activities. When they caused this protein to be synthesized in the anterior margin, they obtained mirror-image duplications. More interestingly, they were able to correlate the time, place, and amount of Sonic Hedgehog gene expression with the classically defined potency of this region to induce the mirror-image duplications.

The relationship between fate map and gene expression map has been of critical concern to evolutionary developmental biology. The temporal priority of the gene expression map over the fate map is seen when genes are functionally deleted from embryos. In these cases, the fate map changes as well ${ }^{19}$ (figure 11.5). The cell lineage map, the fate map, and the gene expression map have been united in this type of experiment, with the gene expression map having priority and explaining the others.

This is critical in evolutionary developmental biology. One of the tenets of evo-devo has been that evolution is predicated upon hereditable changes in development. These changes are therefore usually changes in gene expression. Thus gene expression changes and continuities are the stuff from which much of evo-devo has been made. The case for the inclusion of evolutionary developmental biology into evolutionary biology has been made largely upon the changes and the continuities of gene expression maps. Thus, comparative gene expression maps have played key roles as evidence for the importance of evolutionary developmental biology.

One of the first of these comparative gene expression maps showed the homologous expression of the Hox genes and head transcription factors $^{20}$ between the protostomal arthropods (represented by Drosophila) 


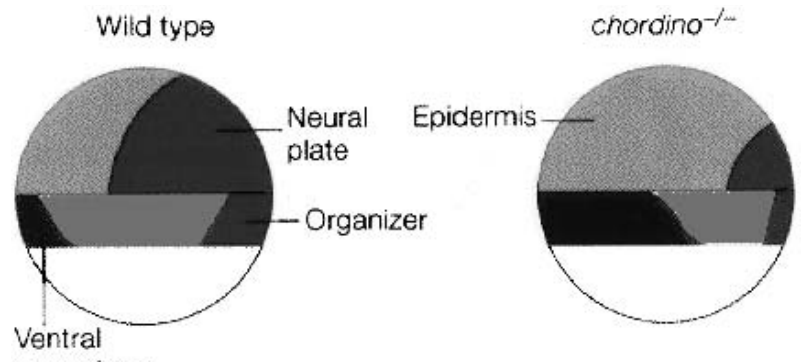

mesoderm

Figure 11.5

Change in fate map of the zebra fish when the Chordino gene is deleted. The Chordino product is important in forming neural (dorsal) ectoderm and dorsal mesoderm. In the absence of this gene, the epidermis expands at the expense of the neural plate, and the ventral and lateral mesoderm expand at the expense of the dorsal (organizer) mesoderm.

and the deuterostomal vertebrates (represented by Mus). (See figure 11.6) This research stressed the similarities of the protostomes and the deuterostomes, showing that not only did the two groups have homologous Hox genes that were in the same order in their respective chromosomes, but also that the geographic order of expression was conserved. The expression pattern of Hox genes throughout the animal kingdom was so similar that Slack and colleagues ${ }^{21}$ proposed that this constituted the fundamental basis of being an animal. (Interestingly, more recent gene expression maps - those presenting Hox gene expression in sponges ${ }^{22}$ - have been used as evidence against this view.)

Moreover, further investigations have demonstrated that variations of this expression pattern can produce morphological changes. Changes in the Hox gene expression map in crustaceans were correlated with the changing number of maxillipeds, and changes in the Hox gene expression pattern in vertebrates correlated with changes in the number of cervical vertebrae. ${ }^{23}$ In some cases, severe alterations all but eliminated the certain constellations of Hox gene expression, and these eliminated the cervical vertebrae as well as the lumbar vertebrae. Thus, in the limbless snakes, the Hox gene expression patterns make the thoracic-ribbed-vertebrae expanded at the expense of the Hox gene patterns allowing other vertebral types. ${ }^{24}$ Similar changes in Hox genes change the structures of arthropods as well, distinguishing the shrimp from the lobster. ${ }^{25}$

Alterations of the Hoxd11 and Hoxd13 expression pattern have even been proposed to account for the formation of the autopod. Figure 11.7 


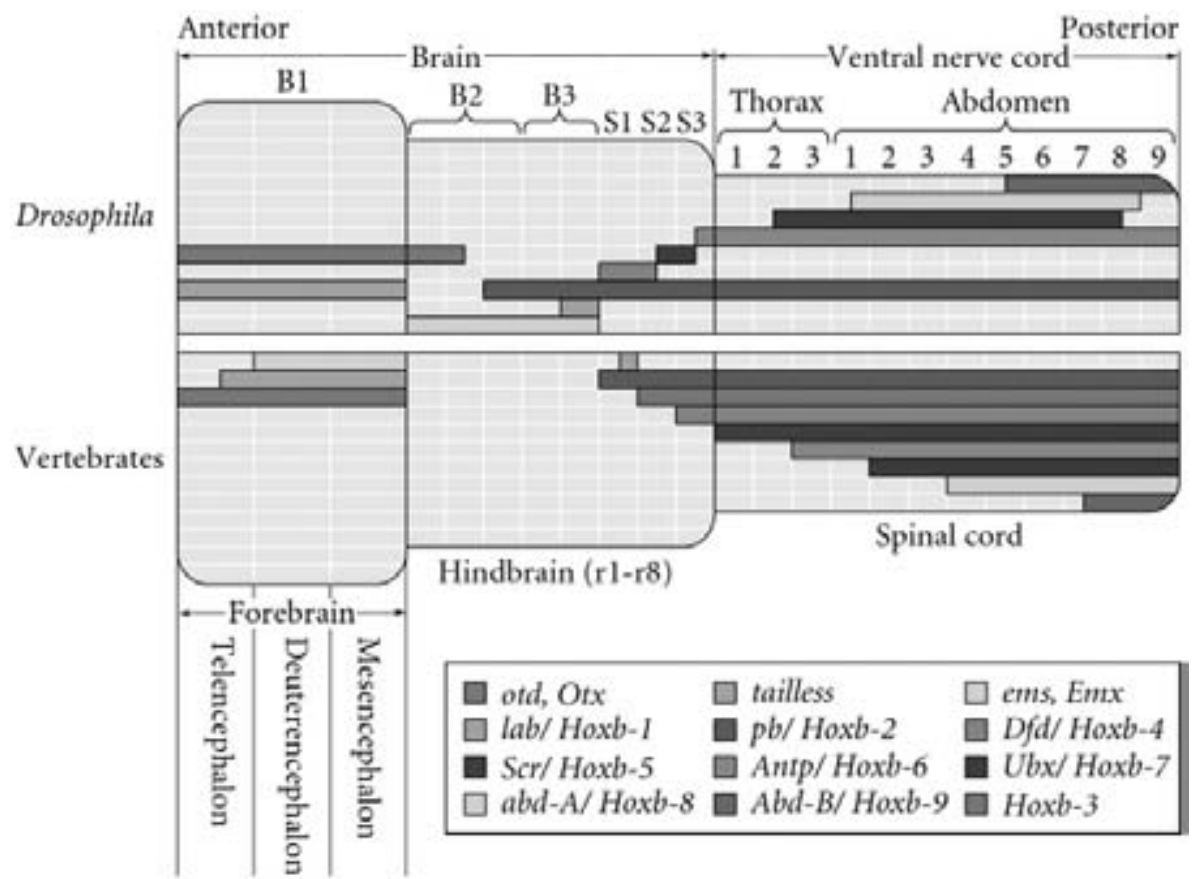

Figure 11.6

Expression of regulatory transcription factors in Drosophila and vertebrates. The Drosophila genes ems, tll, and otd are homologous to the vertebrate Emx, Tll, and Otx genes, respectively. The Hox genes expressed in Drosophila and in vertebrates have similar patterns in their respective hindbrains and neural cords.

depicts a Devonian fantasy of about 350 million years ago. Although there is no way of knowing the Hox gene expression of the lobe-finned fish (or how it might be fruitfully compared with a highly derived modern osteichthyan such as Danio rerio), the alterations in gene expression pattern between modern fish and modern tetrapods, and the importance of Hox genes in specifying limb parts, converged to make the different gene expression maps important evidence for a mechanism by which fish fins could be transformed into tetrapod limbs. ${ }^{26}$

Gene expression maps can also provide clues as to how genes used in one area of development can be recruited to another. For instance, the Distal-less gene, used to define the limb primordia of insects, became coopted to produce the eyespots of butterfly wings, ${ }^{27}$ and the $f g f 10$ gene, used in producing the tetrapod limb bud, may also be utilized for producing the carapacial ridge specific to turtles. ${ }^{28}$ 


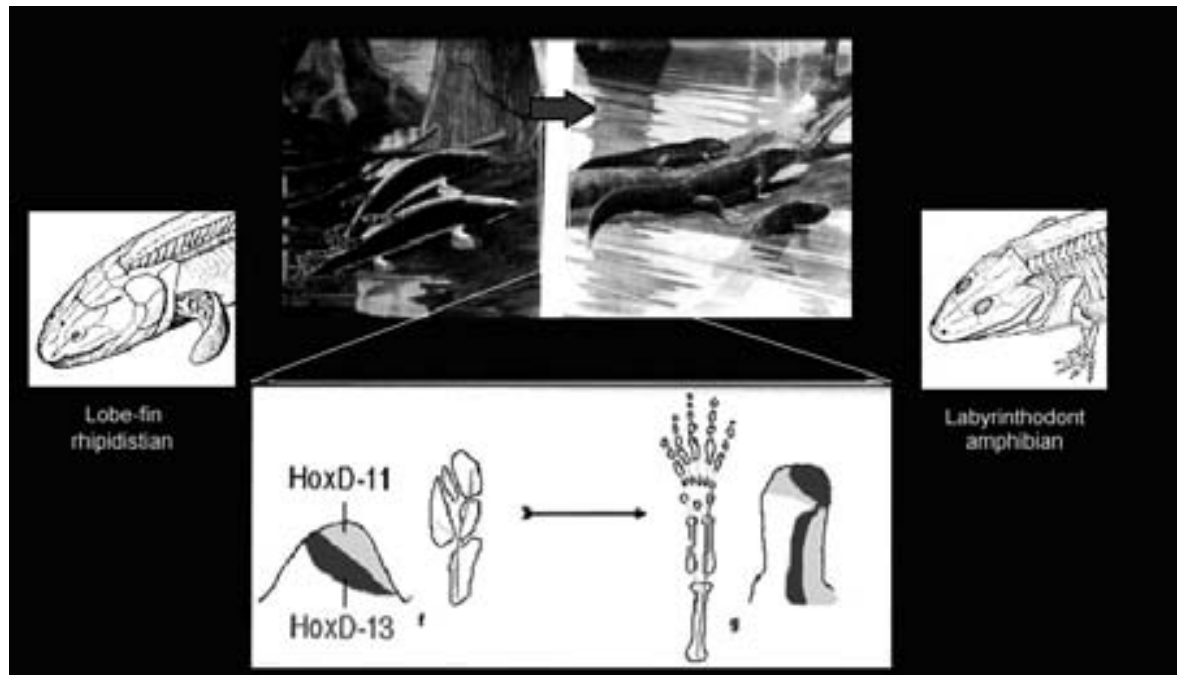

Figure 11.7

In the Devonian, labyrinthodont amphibian tetrapods emerged from an ancestor that was probably similar to lobe-fin rhipidistians. It has been proposed that the change in Hox gene expression patterns at the end of the fin created the autopod and enabled limbs to arise from the stalk of fins.

Gene expression maps can also be used to suggest homologous relationships that are not obvious. For instance, regulatory regions from Amphioxus Hox genes expressed in the anterior neural tube were found to drive spatially localized expression of a reporter gene in vertebrate neural crest cells, in derivatives of neurogenic placodes, and in branchial arches, despite the fact that these cephalochordates lack both neural crest and neurogenic placodes. ${ }^{29}$ This implies that there was already the expression pattern of "head" before there were morphologically cranial structures, and that certain regions of the cephalopod neural tube are homologus to vertebrate brains. Similar research has also homologized the cephalopod endostyle to the vertebrate thyroid gland. In a recent paper, Meinhardt ${ }^{30}$ has used gene expression data to advance the case that the body of the diploblastic and radially symmetrical Hydra is homologous to the brain of triploblastic and bilaterally symmetric animals, and that the most anterior regions of the head form from the pedal ( $N k 2$.1-expressing) domains of a Hydra-like ancestor. Using another cnidarian, Nematostella, Martindale and colleagues (2004) argue that the gene expression patterns indicate that this sea anemone has both bilateral symmetry and a mesodermal germ layer. 
Lowe and colleagues ${ }^{31}$ argue for homologous regions of the vertebrate and hemichordate nervous systems based on gene expression patterns. They use these proposed homologies to interpolate what the nervous system of the bilaterian ancestor of invertebrates and vertebrates may have looked like. Comparative gene expression mapping forms the evidence for Lowe's entire thesis.

Another use of gene expression maps has been to show deep homology. One of the other major principles emerging from evolutionary developmental biology is that analogous structures can be formed by homologous instructions. For instance, the dorsal neural tube of the deuterostomes and the ventral nerve cord of the protostomes appear to be constructed by the same set of gene and gene product interactions, suggesting that nature figured out how to make a nervous system only once. Similarly, there appear to be homologous genes and pathways to specify both insect and vertebrate limbs which have no homologies as walking structures. ${ }^{32}$ In both types of limbs, gene expression maps show that the proximal-distal axis appears to be specified by Fringe (proximal) and Distalless (distal); the dorsal-ventral axis, by Wnt (dorsal) and Engrailed (ventral); and the anterior-posterior axis, by Hedgehog expression (posterior).

\section{New Techniques of Gene Expression Mapping}

Computer-aided technology has been incredibly important in the genemapping community. Some of the greatest advances are in the area of three-dimensional expression-mapping. The first concerns threedimensional reconstructions wherein the computer rapidly and "objectively" realigns embryonic sections so as to make them usable for three-dimensional reconstruction ${ }^{33}$ (figure 11.8). This procedure combines the methodological advantages of whole-mount, in situ hybridization and the high-scale resolution of serial sectioning. After capturing phasecontrast and bright field views of serial sections, one can map in situ hybridization data through a series of algorithms. The subjective interactions of the processor have been eliminated.

Another three-dimensional aid is Geographic Information System (GIS) analysis. Epoxy resin casts of an organ (such as a tooth) are optically sectioned at $25-100 \mu \mathrm{m}$ intervals, using a laser confocal microscope. High-resolution digital elevation models (DEMs) of the organ topology are produced from the image stacks, using the 3Dview version of the NIH-Image software. DEMs can be transferred to GIS software as well as interpreted by surface-rendering computer programs. All traditional mor- 


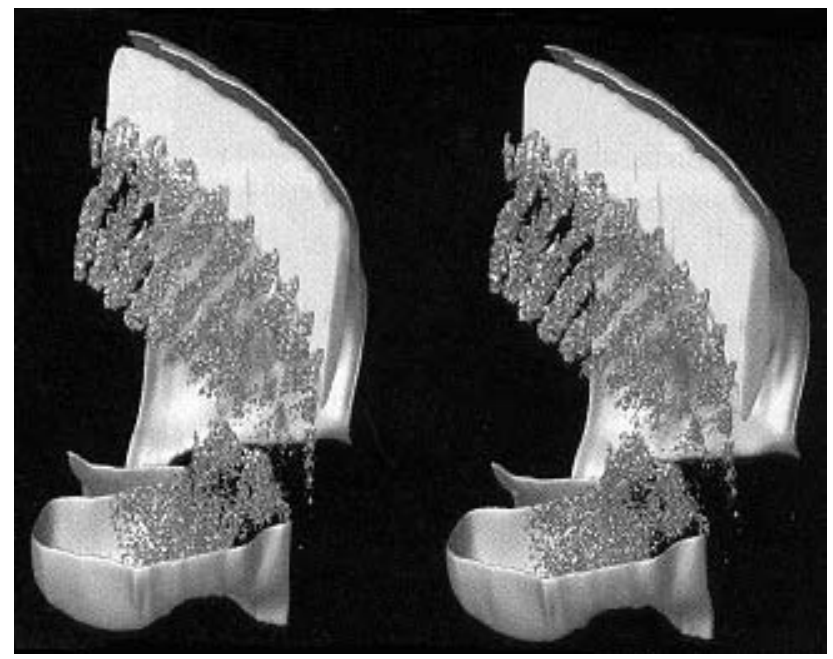

Figure 11.8

Fate mapping of myotome cells (purple) as they enter the limb bud. Computer reconstruction made from $m y f-5$ expression in the developing myotome cells. Crossing your eyes allows you to see a 3-dimensional view. Courtesy of J. Streicher and G. Müller.

phometrical measurements can be obtained from DEMs. However, the total shape data (i.e., DEMs) can be explored with GIS prior to the selection of appropriate measurements. Furthermore, since the DEMs can be stored as a database of organ morphologies, the three-dimensional morphology can be accessed remotely via the Web. Jernvall and his colleagues ${ }^{34}$ have used this technology to measure the development of mammalian teeth. Moreover, they can place on this topography the various gene expression patterns of in situ hybridization.

The GIS technology was designed specifically for landscape topologies in real cartographic mapping, and it has been adopted by ecologists for their surveys. The method and analogy of geographic mapping to gene expression-mapping was made explicitly by Jernvall in his presentation at the SICB meeting in January, 2001 (figure 11.9). In these papers, Jernvall and colleagues have demonstrated that changes in gene expression in enamel knots (analyzed by in situ hybridization) cause the morphological differences between mouse and vole molars (as seen by the DEMs). Expression of $f g f 4, S h h$, and $p 21$ prefigures changes in morphology, and the spatial distribution causes the subsequent location of cusps. This remarkable conclusion is predicated on extremely sophisticated gene expression and fate-mapping correlations. 


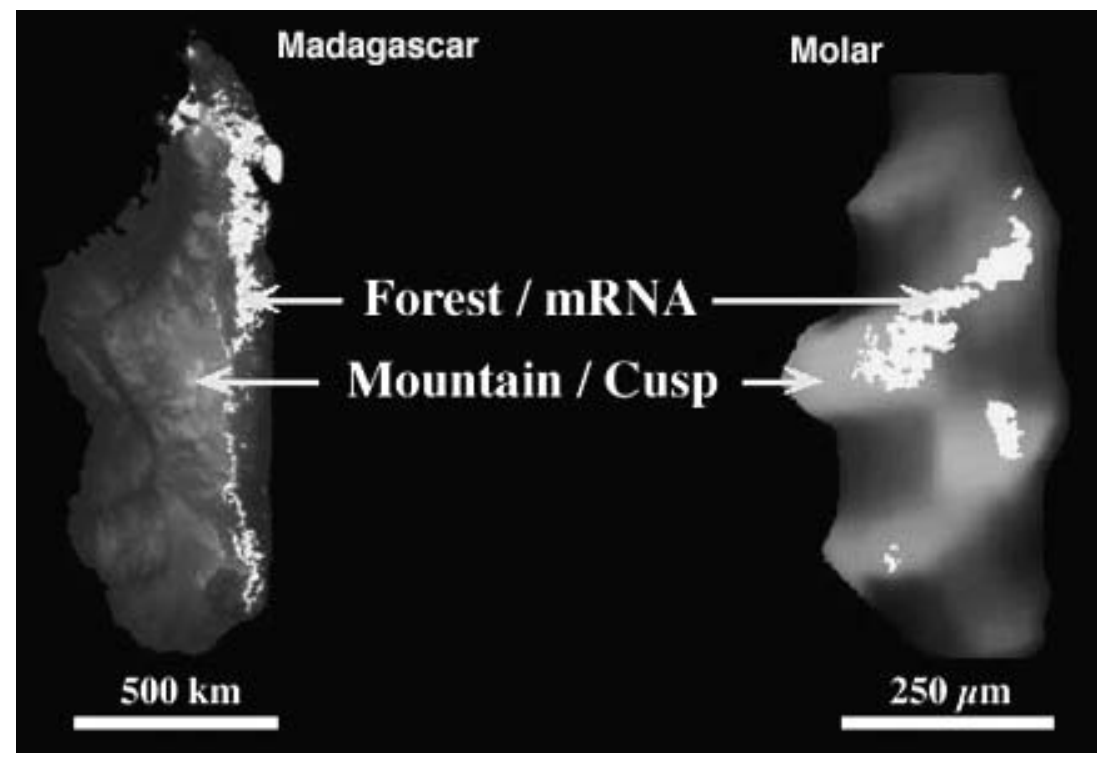

Figure 11.9

Explicit mapping analogy made by Jernvall in his GIS reconsructions of gene expression in the rodent molar. Courtesy of J. Jernvall.

\section{CONCLUSION}

The mapping program in embryology, initiated at the turn of the twentieth century, is an extremely active and important program in contemporary developmental biology. Both fate maps and gene expression maps summarize new data, and organize it in a way that relates it to other data and leads to new research. Mapping has been especially important in providing evidence for evolutionary developmental biology. It not only summarizes the evidence in the field but also serves the functions of relating the new data to classical data (thereby linking a new science to an established science) and of showing the importance of evo-devo to evolutionary biology. New procedures in monitoring gene expression patterns, localizing dyes in certain cells, and graphically representing these patterns have made mapping of paramount importance to developmental biology.

Developmental biologists have long been confronted with "mapping" problems and have solved them in creative ways. Fate maps compressed four-dimensional space onto two dimensions, and video animation is now allowing the temporal dimension to be shown in detail. 
For evolutionary developmental biology, the current challenge is producing a five-dimensional representation: the four standard dimensions of space and time placed into the context of the paleontological temporal dimension.

\section{Notes}

1. Monmonier, 1991.

2. See Galperin, 1998.

3. Vogt, 1929.

4. Vogt was an outdoorsman and was not averse to using geographic metaphors. In 1929, he speaks of Spemann's "conquest of an uncharted territory of knowledge" (Hamburger, 1988, p. 80). The fate maps resemble contemporary anthropological maps depicting the spread of Teutons or Magyars into new areas.

5. See Gilbert, 2000.

6. See Lane and Smith, 1999.

7. Sherwood and McClay, 2001.

8. Bauer et al., 1994.

9. Keller, 1976.

10. Hamburger, 1988.

11. Spemann and Mangold, 1924.

12. Spemann and Schotte, 1932.

13. Tung et al., 1962

14. Wray and Raff, 1990. More recently, Ferkowitz and Raff (2001) have used gene expression mapping to show the importance of Wnt5 expression in the transition from indirect- to direct-developing sea urchins.

15. Keller, 1976; Gont et al., 1993.

16. Vodicka and Gerhart, 1995.

17. Winklebauer and Schürfeld, 1999.

18. Riddle et al., 1993.

19. Kishimoto et al., 1997.

20. See Hirth and Reichert, 1999.

21. Slack et al., 1993. 
22. Schierwater and Kuhn, 1998.

23. Gaunt, 1994; Burke et al., 1995.

24. Cohn and Tickle, 1999.

25. Averof and Patel, 1997.

26. Sordino et al., 1995; Shubin et al., 1997.

27. Brakefield et al., 1996.

28. Loredo et al., 2001.

29. Manzanares et al., 2000.

30. Meinhardt, 2002.

31. Lowe et al., 2003.

32. See Shubin et al., 1997.

33. See Streicher et al., 2000.

34. Jernvall et al., 2000.

REFERENCES

Averof, Michael, and Patel, N. H. 1997. Crustacean appendage evolution associated with changes in Hox gene expression. Nature 388: 682-686.

Bauer, Daniel V., Huang, S., and Moody, S. A. 1994. The cleavage stage origin of Spemann's Organizer: Analysis of the movements of blastomere clones before and during gastrulation in Xenopus. Development 120: 1179-1189.

Brakefield, P. M., Gates, J., Keyes, D., Kesbeke, F., Wijngaarden, P. J., Monteiro, A., French, V., and Carroll, S. B. 1996. Development, plasticity, and evolution of butterfly eyespot patterns. Nature 384: 236-242.

Burke, Ann C., Nelson, C. E., Morgan, B. A., and Tabin, C. 1995. Hox genes and the evolution of vertebrate axial morphology. Development 121: 333-346.

Cohn, Michael J., and Tickle, C. 1999. Developmental basis of limblessness and axial patterning in snakes. Nature 399: 474-479.

Conklin, Edwin G. 1905. The organization and cell lineage of the ascidian egg. Journal of the Academy of Natural Science, Philadelphia 13: 1-119.

Ferkowicz, Michael J., and Raff, R. A. 2001. Wnt gene expression in sea urchin development: Heterochronies associated with the evolution of developmental mode. Evolution and Development 3: 24-33.

Galperin, Charles. 1998. From cell lineage to developmental genetics. History and Philosophy of the Life Sciences 20: 301-344. 
Gaunt, Stephen J. 1994. Conservation in the Hox code during morphological evolution. International Journal of Developmental Biology 38: 549-552.

Gilbert, Scott F. 2000. Developmental Biology, 6th ed. Sunderland, Mass.: Sinauer.

Gont, Linda K., Steinbeisser, H., Blumberg, B., and De Robertis, E. M. 1993. Tail formation as a continuation of gastrulation: The multiple tail populations of the Xenopus tailbud derive from the late blastopore lip. Development 119: 991-1004.

Hamburger, Viktor. 1988. The Heritage of Experimental Embryology: Hans Spemann and the Organizer. Oxford: Oxford University Press.

Hirth, Frank, and Reichert, H. 1999. Conserved genetic programs in insect and mammalian brain development. BioEssays 21: 677-684.

Jernvall, Jukka, Keranen, S.V., and Thesleff, I. 2000. Evolutionary modification of development in mammalian teeth: Quantifying gene expression patterns and topography. Proceedings of the National Academy of Sciences USA 97: 14444-14448.

Keller, Ray E. 1976. Vital dye mapping of the gastrula and neurula of Xenopus laevis. II. Prospective areas and morphogenetic movements of the deep layer. Developmental Biology 51: 118-137.

Kishimoto, Yasayuki, Lee, K. H., Zon, L., Hammerschmidt, M., and Schulte-Merker, S. 1997. The molecular nature of zebrafish swirl: BMP2 function is essential during early dorsoventral patterning. Development 124: 4457-4466.

Lane, Mary C., and Smith, W. C. 1999. The origins of primitive blood in Xenopus: Implications for axial patterning. Development 126: 423-434.

Loredo, Grace A., Brukman, A., Harris, M. P., Kagle, D., LeClair, E. E., Gutman, R., Denney, E., Henkelman, E., Murray, B. P., Fallon, J. F., Tuan, R. S., and Gilbert, S. F. 2001. Development of an evolutionarily novel structure: Fibroblast growth factor expression in the carapacial ridge of turtle embryos. Journal of Experimental Zoology/ Molecular and Developmental Evolution 291: 274-281.

Lowe, Christopher, J., Wu, M., Salic, A., Evans, L., Lander, E., Stange-Thomann, N., Gruber, C. E., Gerhart, J., and Kirschner, M. 2003. Anteroposterior patterning in hemichordates and the origins of the chordate nervous system. Cell 113: 853-865.

Manzanares, Miguel, Wada, H., Itasaki, N., Trainor, P. A., Krumlauf, R., and Holland, P. W. 2000. Conservation and elaboration of Hox gene regulation during evolution of the vertebrate head. Nature 408: 854-857.

Martindale, Mark Q., Pang K., and Finnerty, J. R. 2004. Investigating the origins of triploblasty: Mesodermal gene expression in a diploblastic animal, the sea anemone Nematostella vectensis (phylum, Cnidaria; class, Anthrozoa). Development 131: 2453-2474.

Meinhardt, Hans. 2002. The radially symmetric hydra and the evolution of the bilateral body plan: An old body became a young brain. BioEssays 24: 185-191.

Monmonier, Mark. 1991. How to Lie with Maps. Chicago: University of Chicago Press. 
Riddle, Robert D., Johnson, R. L., Laufer, E., and Tabin, C. 1993. Sonic hedgehog mediates the polarizing activity of the ZPA. Cell 75: 1401-1416.

Schierwater, Bernd, and Kuhn, K. 1998. Homology of Hox genes and the zootype concept in early metazoan evolution. Molecular and Phylogenetic Evolution 9: 375-381.

Sherwood, David R., and McClay, D. R. 2001. LvNotch signaling plays a dual role in regulating the position of the ectoderm-endoderm boundary in the sea urchin embryo. Development 128: 2221-2232.

Shubin, Neil, Tabin, C., and Carroll, S. 1997. Fossils, genes, and the evolution of animal limbs. Nature 388: 639-648.

Slack, Jonathan M. W., Holland, P. W. H., and Graham, C. F. 1993. The zootype and the phylotypic stage. Nature 361: 490-492.

Sordino, Paolo, Van der Hoeven, F., and Duboule, D. 1995. Hox gene expression in teleost fins and the origin of vertebrate digits. Nature 375: 678-681.

Spemann, Hans, and Mangold, H. 1924. Induction of embryonic primordia by implantation of organizers from a different species. In B. H. Willier and J. M. Oppenheimer (eds.), 1974. Foundations of Experimental Embryology, pp. 144-184. New York: Hafner.

Spemann, Hans, and Schotté, O. 1932. Über xenoplatische Transplantation als Mittel zur Analyse der embryonalen Induction. Naturwissenschaften 20: 463-467.

Streicher, Johannes, Donat, M. A., Strauss, B., Sporle, R., Schughart, K., and Müller, G. B. 2000. Computer-based three-dimensional visualization of developmental gene expression. Nature Genetics 25: 147-152.

Tung, T. C., Wu, S. C., and Tung, Y. Y. F. 1962. The presumptive areas of the egg of Amphioxus. Scientia Sinica 11: 82-90.

Vodicka, Marie A., and Gerhart, J. C. 1995. Blastomere derivation and domains of gene expression in the Spemann Organizer of Xenopus laevis. Development 121: 3505-3518.

Vogt, Walther. 1929. Gestaltungsanalyse am Amphibienkeim mit örtlicher Vitalfärbung. II. Teil. Gastrulation und Mesodermbildung bei Urodelen und Anuren. Wilhelm Roux's Archiv für Entwicklungsmechanik der Organismen 120: 384-706.

Winklebauer, Rudolf, and Schürfeld, M. 1999. Vegetal rotation, a new gastrulation movement involved in the internalization of the mesoderm and endoderm in Xenopus. Development 126: 3703-3713.

Wray, Gregory A., and Raff, R. A. 1990. Novel origins of lineage founder cells in the direct-developing sea urchin Heliocidaris erythrogramma. Developmental Biology 141: $41-54$. 